\title{
The E-Commerce Investment and Enterprise Performance Based on Customer Relationship Management
}

Yili Sun, Weifang University of Science and Technology, Weifang, China

Ping Wang, Weifang University of Science and Technology, Weifang, China

\begin{abstract}
In the current dynamic and complex competitive environment, the implementation of enterprise e-commerce plays an important role in the development of external business process activities. Through the internet, information sharing and business process collaboration between enterprises and customers can be realized. This kind of e-service activity based on e-commerce process is particularly important for customers. However, many business managers have some doubts about the implementation of customer service-oriented online business activities because customer serviceoriented online business activities need a lot of IT investment, and the performance of these e-business activities is not easy to measure.
\end{abstract}

\section{KEYWORDS}

Customer Relationship Management Ability, E-Commerce Ability, E-Commerce Investment, Enterprise Performance

\section{INTRODUCTION}

The differentiation and stratification of consumers and the diversification of the demand for products and services, more and more enterprises begin to carry out customer-oriented e-commerce activities, the business model of marketization gradually changes to the business model of customization (Alinejad et al., 2015; Navimipour \& Soltani, 2016; Shami et al., 2015). And the organizational structure also changes from the traditional single and independent organizational structure to the current dominant network organizational structure transformation (Jason, 2015; Wang et al., 2015; Xun, 2015). At present, enterprises cannot rely on their own capabilities to adapt to the changing business environment (Cokins, 2017; Kizu et al., 2017). They need to rely on the joint strength with partners or customers to integrate the stakeholders involved in business processes, such as customers, suppliers, distributors and retailers, into a close value chain or reintegrate complementary resources and allocate them in the supply chain of enterprises. Now online business process cooperation, so as to strive for more cross time and space capabilities and competitive advantages (Lin, 2017; Mamun \& Nasir, 2017; Sun \& Yano, 2015).

The interactivity and openness of Internet-based e-commerce technology in inter organization data transmission make them have a very important impact on enterprise management practice. In fact, the Internet has surpassed the application of information technology such as cross organization information system (IOS) and data exchange system (EDI) in information sharing ability and cost 
reduction (Bogicevic et al., 2016; Christiam \& Garcia, 2018; Soltanizadeh et al., 2016). For example, the application of enterprise online after-sales system, it can make enterprises solve problems for customers in time through the network. The automation of after-sales service can reduce the cost of enterprises and improve the efficiency of enterprises (Kyung et al., 2016; Octavia et al., 2017; Rahim et al., 2017). In the early days, online communication based on Web replaced the communication mode of fax and letter. The application of virtual community and community forum can provide help for enterprises to mine potential customers and study customer needs. In the e-commerce environment, the core of organization resources are not limited within the enterprise (Al-Qeed et al., 2017; Edgeman, 2015; Hsin et al., 2016). They have been extended to the outside of the organization and embedded in the activities and processes outside the organization (Alamsyah \& Indraswari, 2017; Bhat \& Darzi, 2016; Orenga-Roglá \& Chalmeta, 2016). E-commerce application based on Web makes business process transition from inside to outside (Prisha et al., 2017). In fact, the cross application of business processes among enterprises is very common in supply chain (Hua, 2016). The production of enterprise IT value is not independent, and the individuals involved in business activities are interrelated. The current situation and existing problems reflect the dynamic process and behavior law of customer service-oriented online business activities, and eliminate the concern of enterprise managers for implementation (Iqbal, 2015). Customer service oriented online business activities provide effective e-commerce implementation strategies for enterprise managers, which has important practical management significance.

George et al. used simulation experiments to explore the impact of EDI on corporate performance. $\mathrm{Wu}$ et al. collected sample data from US companies and used regression analysis to explore the mechanism of e-commerce promoting corporate performance. Zhu et al. studied the influence relationship between e-commerce capabilities and information technology infrastructure and corporate performance (Shan et al., 2016). Ren Feng et al. used the structural equation model to study the relationship between network usage and marketing activities and customer relationship management. Research has shown that network usage can improve marketing activities and customer relationship management capabilities. Apigian et al. put forward five aspects of enterprise e-commerce application, and believed that only when enterprises use e-commerce combined with business processes can they exert their effectiveness. Shao Bingjia and others studied the impact of e-commerce activities on the performance of Chinese IT listed companies (Li et al., 2016). Saini et al. put forward several capabilities that companies should have to achieve high-level performance, including the ability to use information technology. Zhuang et al. proposed that the use of e-commerce as a technical resource can have an important impact on corporate performance. More scholars study the direct effects between e-commerce and performance, while fewer scholars consider the influence of intermediary variables in it; most literature studies use marketing performance or financial performance to measure performance, which cannot fully reflect the improvement of e-commerce corporate performance effects (Wu, 2016).

There are three innovations in this paper: (1) The relationship between E-B capability and its dimensions, CRM capability and its dimensions is clarified. CRM and E-B are hot topics in business and academic circles. The impact model of e-commerce and corporate performance is more complex and involves many variables. For models with many variables and complex relationships, it is more suitable to use structural equations to build models. At present, there are some shortcomings in the research on the impact of e-commerce applications on corporate performance: one is the lack of research on intermediate variables; the other is that the impact of performance cannot be fully measured; the third is the impact of defects in traditional regression analysis, factor analysis and other data analysis methods. Therefore, based on previous scholars' research, this article introduces marketing capabilities as an intermediary variable, and uses a balanced scorecard system to measure corporate performance, constructs a structural equation model of e-commerce application and corporate performance impact, and studies the relationship between e-commerce application and corporate performance Influence the relationship. 


\section{PROPOSED METHOD}

\subsection{E-Commerce}

Enterprise performance can be understood from two aspects: one is result-oriented performance, which refers to the output records produced by a specific job function or activity within a specific time; the other is behavior-oriented performance, It refers to the actions or behaviors that are related to the goals of the enterprise and can be measured according to the individual's ability (that is, the degree of contribution). Enterprise performance is the performance of the enterprise, or the achievements of the enterprise. They define "corporate performance" as follows: corporate performance refers to the fact that under certain environmental conditions and within a certain period of operation, an enterprise can use its own capabilities to compete in the market, technological progress, profit, expense, scale, etc. through its own behavior. The state of reality reached by aspects. Therefore, high-level e-commerce is used instead. In this stage, e-commerce is not only limited to the purchase and sale of products or services, but also includes a variety of online businesses such as customer service, business cooperation, e-learning, etc. Accordingly, the investment in e-commerce technology has expanded from the initial investment in related e-commerce applications, including computer system, payment, logistics, etc., including all foreground and background applications and processes, which can help enterprises business transactions.

The investor refers to whether the enterprise making e-commerce investment is independent or has strategic partners; the investment mode refers to whether the enterprise makes one-time investment or staged continuous investment when making e-commerce investment; the investment content refers to the development cost (such as hardware, software, network, etc.), E-B technical personnel training, process transformation and maintenance costs. E-B investment shall consider all factors affecting investment income, including E-B development cost, personnel training cost, process transformation cost and maintenance cost. The research on the type and stage of E-B investment is based on two standards: the direction of follow-up investment and the composition of investors (Figure 1).

Enterprise capability refers to the combination of skills and knowledge that enterprises acquire, allocate and utilize various resources to achieve outstanding performance. It is often embedded in the organizational process, and effective cooperation with other activities, which is the key to establish competitive advantage E-B capability as an enterprise capability, closely related to E-B resources, and embedded in the organization's business processes. Because each enterprise has different resources, embeddedness and matching degree, it will form its own unique ability. The rapid development of e-commerce, with its own convenient and fast advantages, has won the trust of consumers. The buyer and the seller do business online through information technology and do not meet each other. However, the investment results of many e-commerce enterprises show that some enterprises' investment in e-commerce not only does not bring about the improvement of enterprise performance, but also leads to the decline of enterprise competitiveness. The research based on the dynamic energy theory shows that the lack of e-commerce ability is the reason why the investment efficiency of e-commerce cannot be improved. E-B investment is not only a simple direct relationship to the improvement of enterprise performance, enterprises can improve enterprise performance only if they have heterogeneous resources that are difficult to be imitated by competitors. However, the research on e-b capability is not deep enough at present, and there are many dimensions that have not formed a consensus on the connotation and composition of E-B capability, but so far there is no unified statement. However, there are still some common points in the basic understanding of e-commerce characteristics, that is, e-commerce ability refers to the ability of enterprises to carry out activities related to operation and marketing in the Internet environment, and also involves the management ability to share information and process collaboration with cooperative enterprises. Although enterprise management ability and technical resources are the important embodiment of enterprise e-commerce ability, from the perspective of long-term development, enterprise level planning is also the embodiment of ability. 


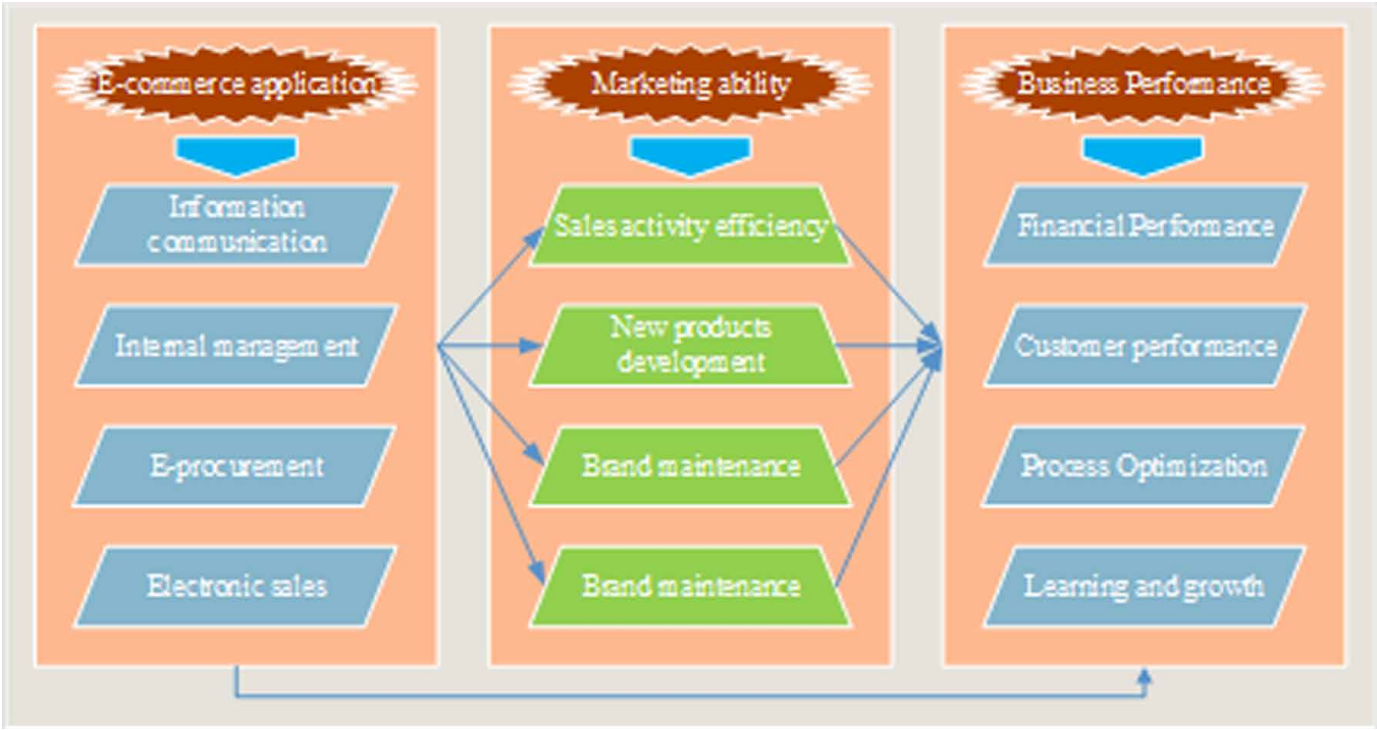

Customer relationship management increases opportunities for enterprises to use data and information to understand customer needs and create value. CRM is a cross functional organizational process, which requires enterprises to integrate business processes, personnel, operations, information, technology and application support and other market capabilities. This further reveals that CRM is not only a technology, but also a unique ability formed through integration with other organization resources. As a kind of enterprise capability, CRM capability is embedded in the CRM activities of enterprises, which reflects that enterprises identify attractive customers and potential customers, establish and maintain the relationship with customers, and transform it into the skill and knowledge combination of customer level benefits. The ability of CRM has a direct impact on the competitiveness of enterprises. It is the key to improve market share and obtain excess profits. Because CRM activities include the acquisition and analysis of customer information, the establishment, maintenance and return of customer relationship, and the use of customer data, its ability is a multi-dimensional concept.

\subsection{Relevant Theories}

Resource-based view is one of the most influential theories in the field of strategic management. With the further development of this theory, some scholars associate it with organizational performance, and make different researches on resource characteristics. The concept of CRM refers to the process of attracting customers, maintaining and developing customer relationships. These long-term customer relationships are the necessary conditions to increase the profits of enterprises. From the perspective of ability, CRM is the ability of enterprises to predict customer needs, formulate market strategies, identify attractive customers, establish and maintain relationships, and transform them into enterprise value. The acquisition of these valuable information requires enterprises to integrate human resources, operations, information and various technologies. Therefore, CRM is not only a technology, but also a capability to integrate various customer technical resources. Although its technology is a necessary resource to improve enterprise performance, the definition and concept of CRM reveal that CRM is the result of continuous development and integration of customer information, its technology and marketing concept. From the perspective of capability, CRM emphasizes that enterprises must invest in the development and acquisition of resources, so that enterprises can use these resources to predict 
customer behavior and formulate corresponding strategies. Therefore, the unique ability of enterprises to integrate resources is the key to improve performance.

The analysis framework of the impact of e-commerce on corporate performance currently mainly includes value chain theory, transaction cost theory and three viewpoints based on corporate resources. The first is the value chain theory. Value chain theory believes that the use of e-commerce by companies can create value in certain links of the value chain. Companies use the Internet and information technology to increase service value, improve operational efficiency, and expand market scope to help companies improve performance and gain competitive advantages. The second view is the theory of transaction costs. Transaction cost theory believes that the effective use of e-commerce by enterprises can achieve the effect of reducing transaction costs. It is demonstrated from the perspective of transaction cost economics that e-commerce can increase performance. The third view is based on the view of corporate resources. RBV theory believes that e-commerce, as a supplementary and specific resource for enterprises, can become a new source of value creation for enterprises.

The acquisition of these valuable information requires enterprises to integrate human resources, operations, information and various technologies. Therefore, CRM is not only a technology, but also a capability to integrate various customer technical resources. Although its technology is a necessary resource to improve enterprise performance, the definition and concept of CRM reveal that CRM is the result of continuous development and integration of customer information, its technology and marketing concept. From the perspective of capability, CRM emphasizes that enterprises must invest in the development and acquisition of resources, so that enterprises can use these resources to predict customer behavior and formulate corresponding strategies. Therefore, the unique ability of enterprises to integrate resources is the key to improve performance.

In the research of E-B capability, CRM capability and enterprise performance, there are few detailed studies in the existing research results. Most of them are about the research of E-B capability or CRM capability on enterprise performance. They think that E-B capability or CRM capability has an important influence on enterprise's long-term competitive advantage and performance improvement. The improvement of E-B capability is helpful to better implement CRM activities, and the improvement of CRM capability is inseparable from abundant E-B resources, as shown in Figure 2.

Figure 2. Theoretical model of relationship between CRM capability and EB investment and enterprise performance

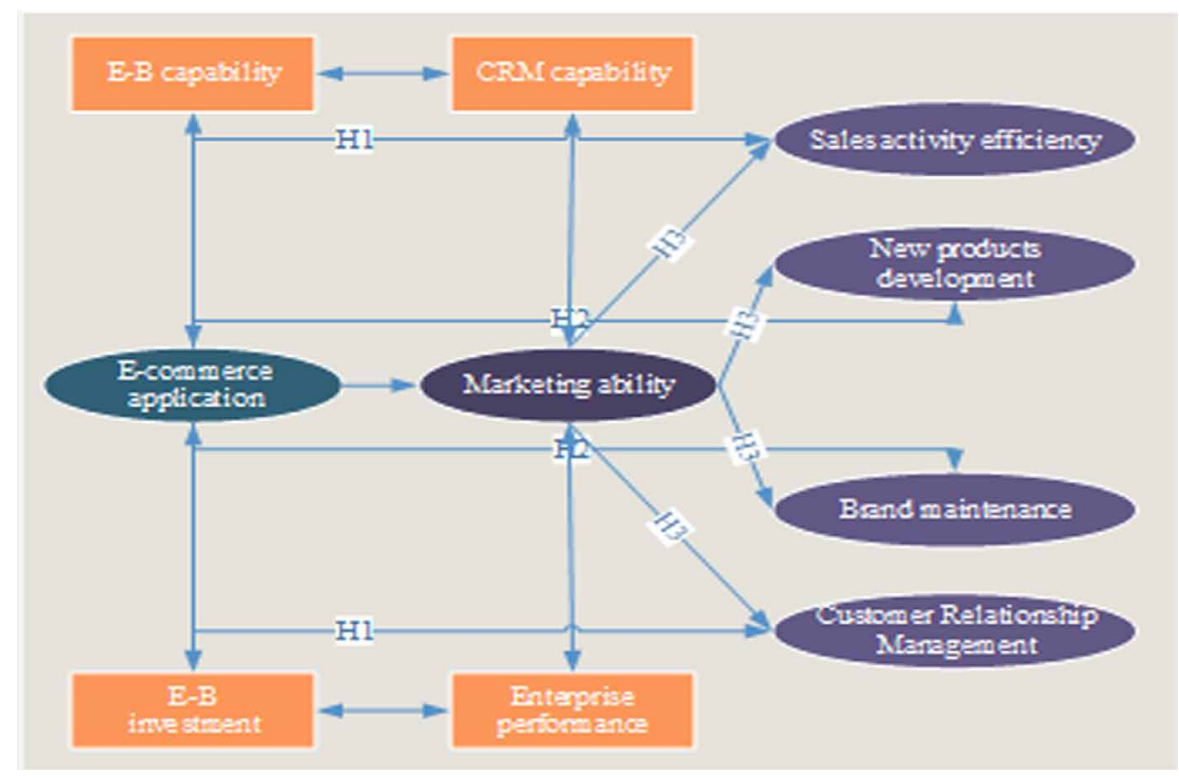


From the perspective of resources and capabilities, this paper puts forward that enterprise performance consists of the transformation of these resources into resources and capabilities. In the past decade, e-commerce technology has developed rapidly. E-commerce is one of the hot topics in manufacturing industry. E-commerce is the advanced stage of e-commerce operation in the primary e-commerce, and it is the process of assisting all the foreground and background applications of e-commerce market transactions. The evolution of e-commerce from one mature stage to another requires enterprises to continuously learn and develop new capabilities to meet the needs of different stages. E-commerce applications based on Internet technology can realize e-commerce functions such as network sales, online shopping, online collaboration, and network information sharing through docking with enterprises. It enables enterprises to develop from the organization of physical network and computer network to the organization connecting different business partners. Therefore, the application of e-commerce is not only an investment choice, but also a necessary investment for enterprises to maintain competitiveness. Whether to invest in e-commerce or not, we should not only consider the benefits brought by e-commerce to enterprises, but also consider the use cost, maintenance cost and capital constraint of e-commerce in the field of information technology. There is a certain relationship between IT investment and enterprise performance. However, the application of information technology and e-commerce is different. E-commerce pays more attention to business activities with suppliers and customers, and cannot explain the phenomenon of e-commerce application with mature results of its research.

\section{EXPERIMENTS}

\subsection{Experimental Data Set}

This research questionnaire is distributed in many ways: first, the tutor project team members send the questionnaire to the relevant enterprises in paper or electronic form, and ask the respondents to fill it out and return it to the relevant project team members; second, send the paper questionnaire to the students of University MBA and EMBA, so that those who are in charge of the enterprise can fill it out and recycle it on the spot; finally, send the paper questionnaire to the graduates and return it to the relevant project team members. The University Management Master's, masters and undergraduates who are engaged in relevant work shall issue electronic questionnaires. The research data is collected by means of questionnaires, which are mainly oriented to enterprises and mainly faceto-face interviews. The questionnaires are mainly oriented to the marketing management personnel of the enterprises. 400 questionnaires were distributed to many companies in various cities, and 256 questionnaires were recovered. The number of invalid questionnaires was 54 and the number of valid questionnaires was 202. The response rate and effective response rate of the questionnaire were $64.00 \%$ and $50.50 \%$. Descriptive statistics of the survey questionnaire on the industry, asset size, and number of employees of the surveyed company. Among the surveyed companies, manufacturing, construction, information transmission, computer services and software, wholesale and retail, real estate, leasing and business services, and others accounted for $42.78 \%, 4.44 \%, 13.33 \%, 9.44 \%$, and 3.33 , respectively. $\%, 7.22 \%$ and $19.44 \%$; from the perspective of the scale of corporate assets, under 5 million yuan, large-scale 5.0-10 million yuan, 1001--50 million yuan and more than 50 million yuan accounted for $15.00 \%, 23.89 \%$ and $36.11 \%$ of the sample respectively And $25.00 \%$; companies with more than 1,000 employees accounted for one third of the total, $37.22 \%$. The result of the adjustment is shown in Figure 3.

This paper constructs the enterprise performance evaluation index system and establishes the theoretical model of this study. The on-site distribution and recovery of questionnaires can effectively control the filling and recovery of the questionnaires, with a recovery rate of $50.56 \%$ and an effective rate of $41.11 \%$; 480 questionnaires were distributed to University MBA students, including 93 invalid addresses and 293 non returned ones during their working period, with a recovery rate of $19.58 \%, 9$ 


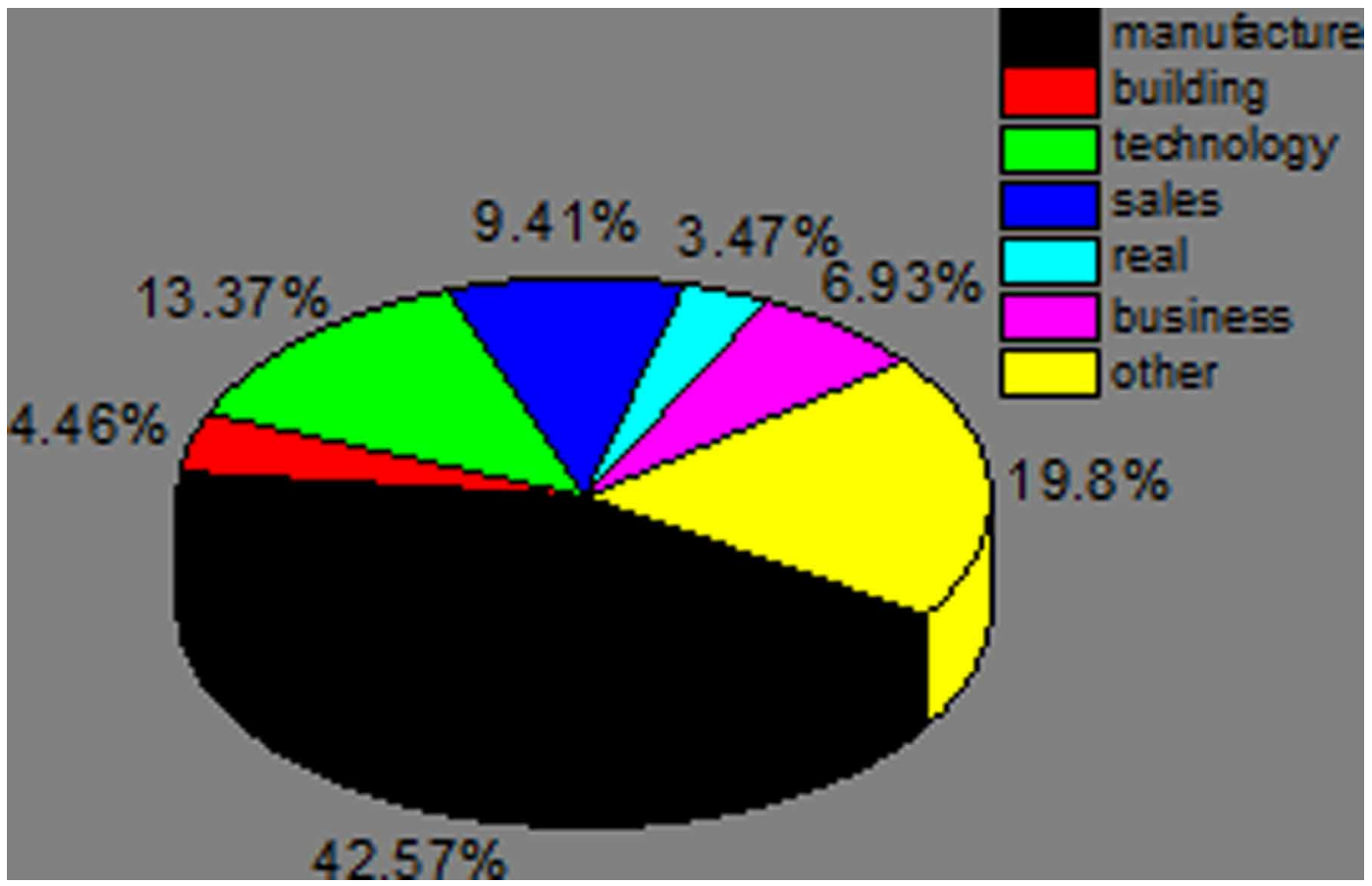

effective ones, and an effective rate of $1.88 \%$. See the distribution and recovery of the questionnaires in this study Table 1. Only 79 valid data are included in this part of data, as shown in Table 1. A total of 148 valid questionnaires were collected by the three methods, which met the requirements of the study design. In addition, due to the specific financial problems of the company involved in E-B investment, there are many missing values.

Table 1. Distribution and recovery of questionnaire

\begin{tabular}{|c|l|l|l|}
\hline Distribution object & $\begin{array}{c}\text { Number of } \\
\text { questionnaires }\end{array}$ & $\begin{array}{c}\text { Questionnaire } \\
\text { recovery rate }\end{array}$ & $\begin{array}{c}\text { Effective questionnaire } \\
\text { rate }\end{array}$ \\
\hline Regional enterprises & 270 & $39.63 \%$ & $24.07 \%$ \\
\hline MBA, EMBA & 180 & $50.56 \%$ & $41.11 \%$ \\
\hline Previous MBA, master's degree & 480 & $19.58 \%$ & $1.88 \%$ \\
\hline Total & 930 & $31.40 \%$ & $15.91 \%$ \\
\hline
\end{tabular}

\subsection{Sample Characteristics}

Most of the enterprises involved in this study have been established for 5-20 years, accounting for $68.92 \%$ of the total number of enterprises, of which $35.81 \%$ have been established for $5-10$ years, indicating that most of the enterprises under investigation have not been established for a long time; there are many enterprises in the manufacturing of electrical equipment, chemical raw materials and chemical products, accounting for $40.54 \%$; nearly half of the enterprises with assets of more than 50 
million yuan, accounting for $45.95 \%$ and more than $1 / 3$ (42.57\%) of the enterprises under investigation there are more than 1000 employees.

\subsection{Reliability and Validity of The Questionnaire}

Using SPSS23.5 for factor analysis, the KMO value is 0.854, and the Bartlett hemisphere test is less than 0.005 . The test shows that the questionnaire is suitable for factor analysis. Figure 4 shows the total variance interpretation measurement results. There are 6 feature values greater than 1 , explaining $71.251 \%$ of the total variance, indicating that the overall validity of the questionnaire is good. The commonly used reliability test methods are $\alpha$ coefficient method and half confidence method in the field of social science research or journals, and the utilization rate of $\alpha$ coefficient is very high. Therefore, the reliability of the scale was judged by $\alpha$ - coefficient.

Figure 4. Variance explained

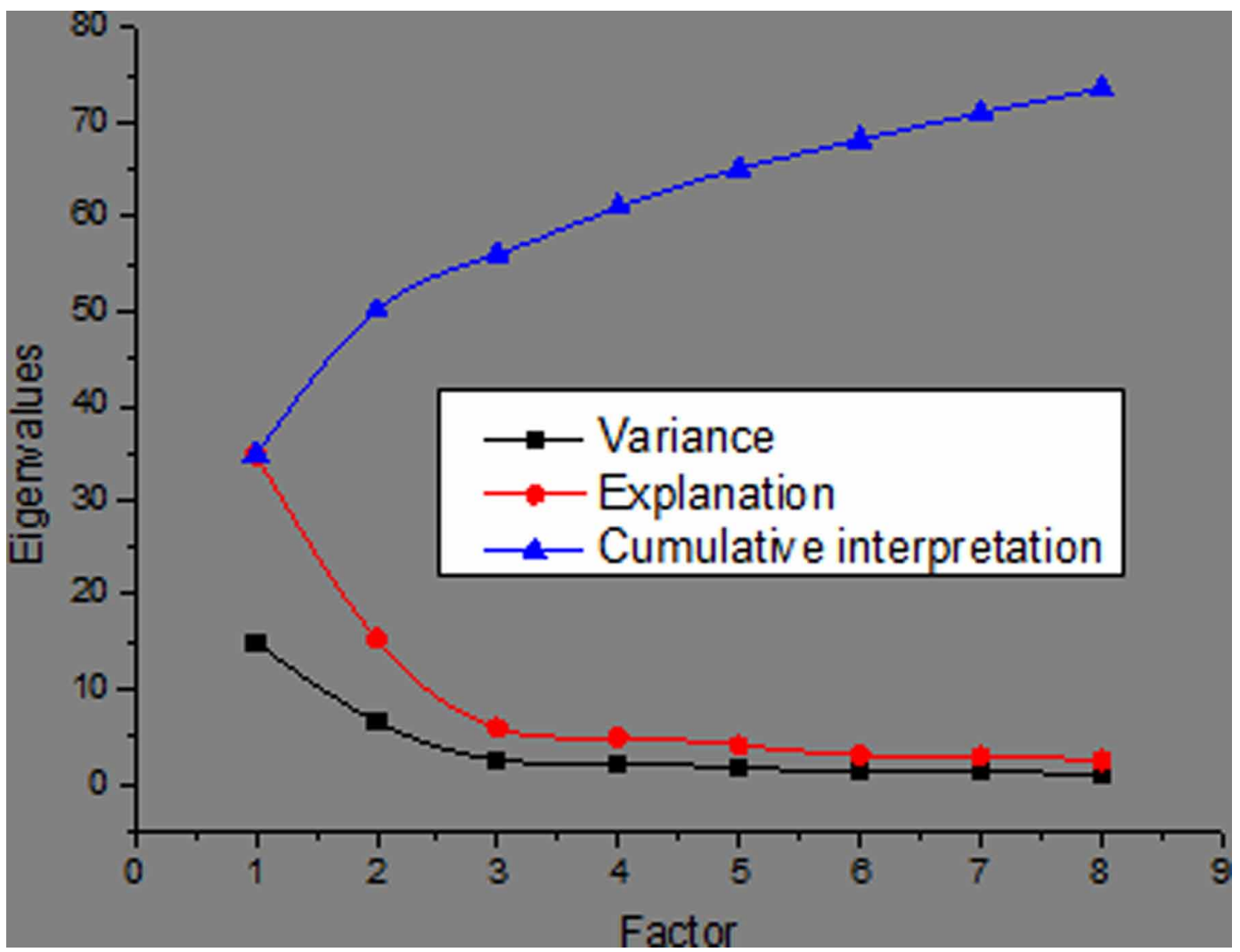

\section{DISCUSSION}

\subsection{Analysis of The Relationship Between E-B Capability and CRM Capability}

Taking E-B ability as independent variable and CRM ability and its sub dimensions as dependent variable, the linear regression analysis of sample 1 is shown in Figure $5(\mathrm{R} 2=0.119, \mathrm{f}=19.754, \mathrm{P}$ $<0.05 ; \mathrm{R} 2=0.146, \mathrm{f}=24.967, \mathrm{P}<0.05 ; \mathrm{R} 2=0.075, \mathrm{f}=11.896, \mathrm{P}<0.05 ; \mathrm{R} 2=0.116, \mathrm{f}=19.188$, $\mathrm{P}<0.05 ; \mathrm{R} 2=0.042, \mathrm{f}=6.428, \mathrm{P}<0.05)$. The regression model results show that $\mathrm{E}-\mathrm{B}$ ability and 


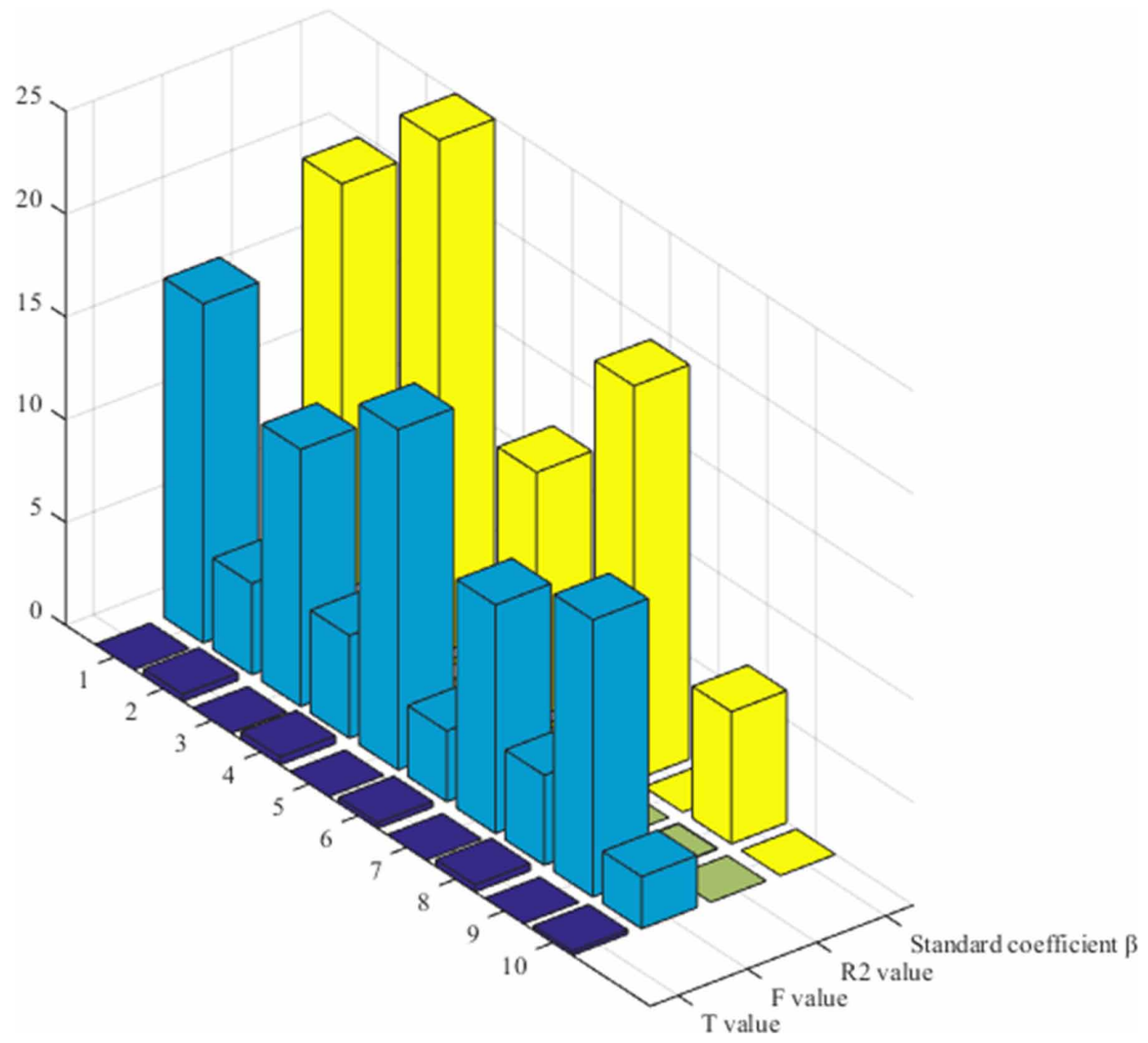

CRM ability and its sub dimensions are in a positive phase close $(\gamma=0.345, \mathrm{t}=4.445, \mathrm{P}<0.05$; $\gamma=0.382, \mathrm{t}=4.997, \mathrm{P}<0.05 ; \gamma=0.274, \mathrm{t}=3.449, \mathrm{P}<0.05 ; \gamma=0.341, \mathrm{t}=4.380, \mathrm{P}<0.05 ; \gamma=$ $0.205, \mathrm{t}=2.535, \mathrm{P}<0.05)$.

This paper finds that E-B ability has a significant impact on CRM ability, that is, the ability of enterprises to integrate and apply E-B resources can improve customer service ability and maintain long-term CRM ability, which is consistent with the existing research. E-B resources are the basis of CRM ability formation. E-B port stores a lot of consumer information, which is an important source of customer behavior analysis. Through these e-commerce technologies, enterprises can not only share information with suppliers, but also analyze consumer behavior, find problems in products or services, correct them in time, and provide data support for the further design and development of new products, so that enterprises can maintain good customer relationship management for a long time and gain lasting competitive advantage. The research shows that E-B capability and its sub dimensions have a significant impact on CRM capability and its sub dimensions. That is to say, the impact of E-B capability on CRM capability is that abundant E-B resources provide a large number of data support for enterprises to analyze customer behavior, predict current and potential customer needs, preferences and other factors, maintain customer relationship, and maximize enterprise profits. 
Thus, the ability of enterprise customer knowledge management is enhanced. Through CRM system, ERP system, social media and other interactive E-B technical resources, enterprises can communicate with customers in a timely manner, understand customers' needs or dissatisfaction, enhance customers' contact ability, improve customers' ability to win and return, discover customers that have been or will be lost in time, so as to carry out scientific management in the future; from various E-B should use ports to get a lot of interaction. The marketing of more advanced products can be carried out accurately, that is to say, the upgrading ability of customers can also be strengthened. It can be seen that the acquisition and enhancement of enterprise CRM capability are inseparable from a large number of E-B technical resources and their strategic planning and management capabilities.

\subsection{Relationship Analysis}

Take customer relationship management ability as the intermediary variable, carry out linear regression analysis on sample I: the F value in the model reaches the significant level of 0.001 , indicating that the overall explanatory variation of the model reaches the significant level, while the E-B ability also reaches the significant level $(\gamma=0.602, \mathrm{t}=9.392, \mathrm{P}<0.05)$, as shown in Figure 6 , indicating the relationship between the E-B ability and enterprise performance. It plays an intermediary role in the relationship.

Figure 6. Model CRM capability mediation

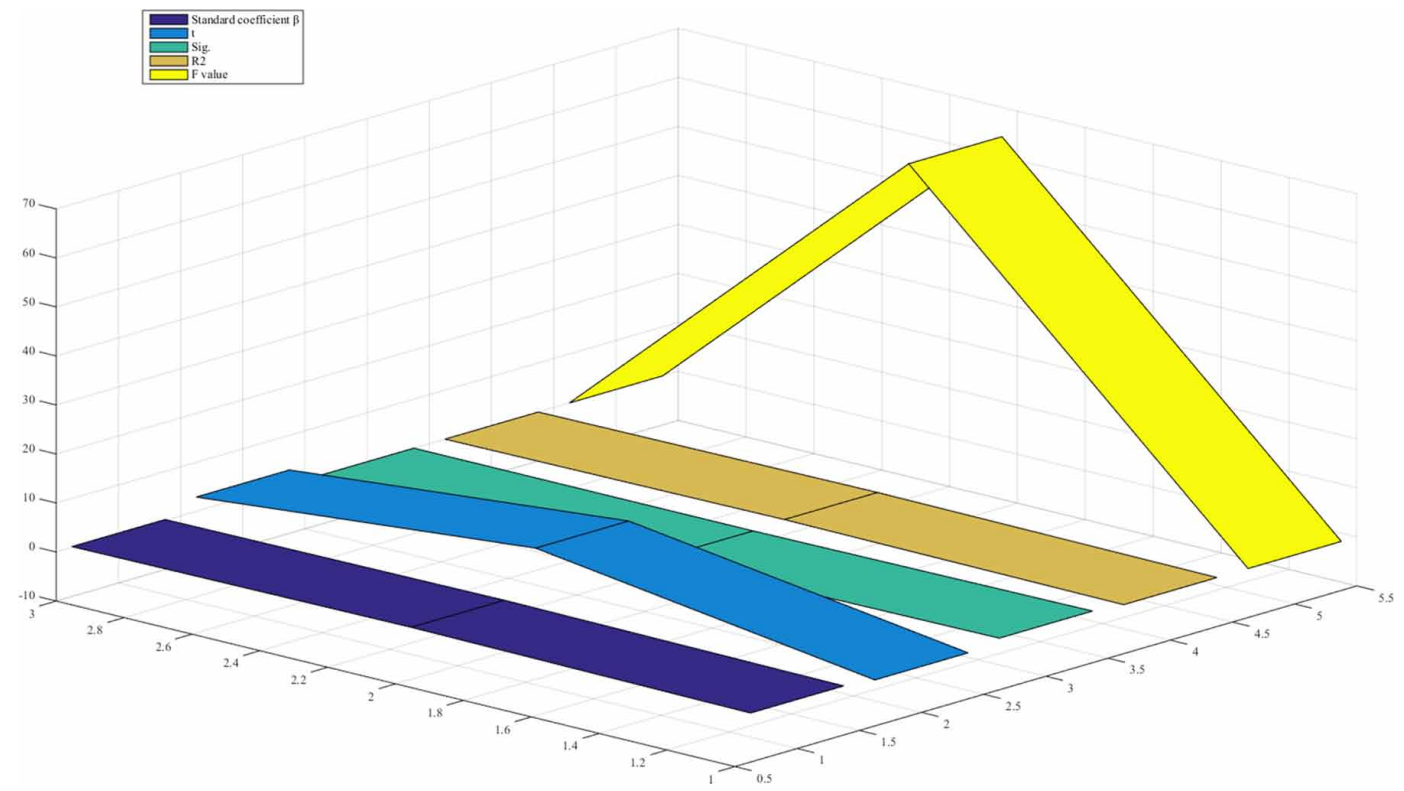

In order to further verify the mediating role of each marketing sub-capacity in the use of e-commerce on corporate performance, the study builds a model of the mediating effect of each sub-capability of marketing. The use of e-commerce significantly positively affects the efficiency of sales activities, new product development, and brand maintenance. And customer relationship management. After adding the four intermediary variables, the use of e-commerce has a significant impact on corporate performance, indicating that the intermediary variables should play a part of the intermediary role in the impact of e-commerce use on corporate performance. The improvement of ability means the improvement of customer data application and management ability, that is, the 
continuous enhancement of data collection, application and analysis ability, which enables enterprises to interact with customers in a timely manner, find out the deficiencies in products or services, and guide the prediction of new products in the future, reflecting the ability of enterprises to obtain business value by reasonably using and managing E-B resources and improving CRM ability Power.

Taking E-B management ability as independent variable and CRM ability and its sub dimensions as dependent variable, the linear regression analysis of sample I is shown in Figure 7 (R2 $=0.091$, $\mathrm{f}=14.617, \mathrm{P}<0.05 ; \mathrm{R} 2=0.113, \mathrm{f}=18.690, \mathrm{P}<0.05 ; \mathrm{R} 2=0.048, \mathrm{f}=7.414, \mathrm{P}<0.05 ; \mathrm{R} 2=$ $0.095, \mathrm{f}=15.261, \mathrm{P}<0.05 ; \mathrm{R} 2=0.034, \mathrm{f}=5.189, \mathrm{P}<0.05)$. Regression model showed that E-B management ability was positively correlated with CRM ability and its sub dimensions $(\gamma=0.301$, $\mathrm{t}=3.823, \mathrm{P}<0.05 ; \gamma=0.337, \mathrm{t}=4.323, \mathrm{P}<0.05 ; \gamma=0.220, \mathrm{t}=2.723, \mathrm{P}<0.05 ; \gamma=0.308, \mathrm{t}=$ $3.907, \mathrm{P}<0.05 ; \gamma=0.185, \mathrm{t}=2.278, \mathrm{P}<0.05)$.

Figure 7. E-B management ability and CRM ability and their sub dimensions

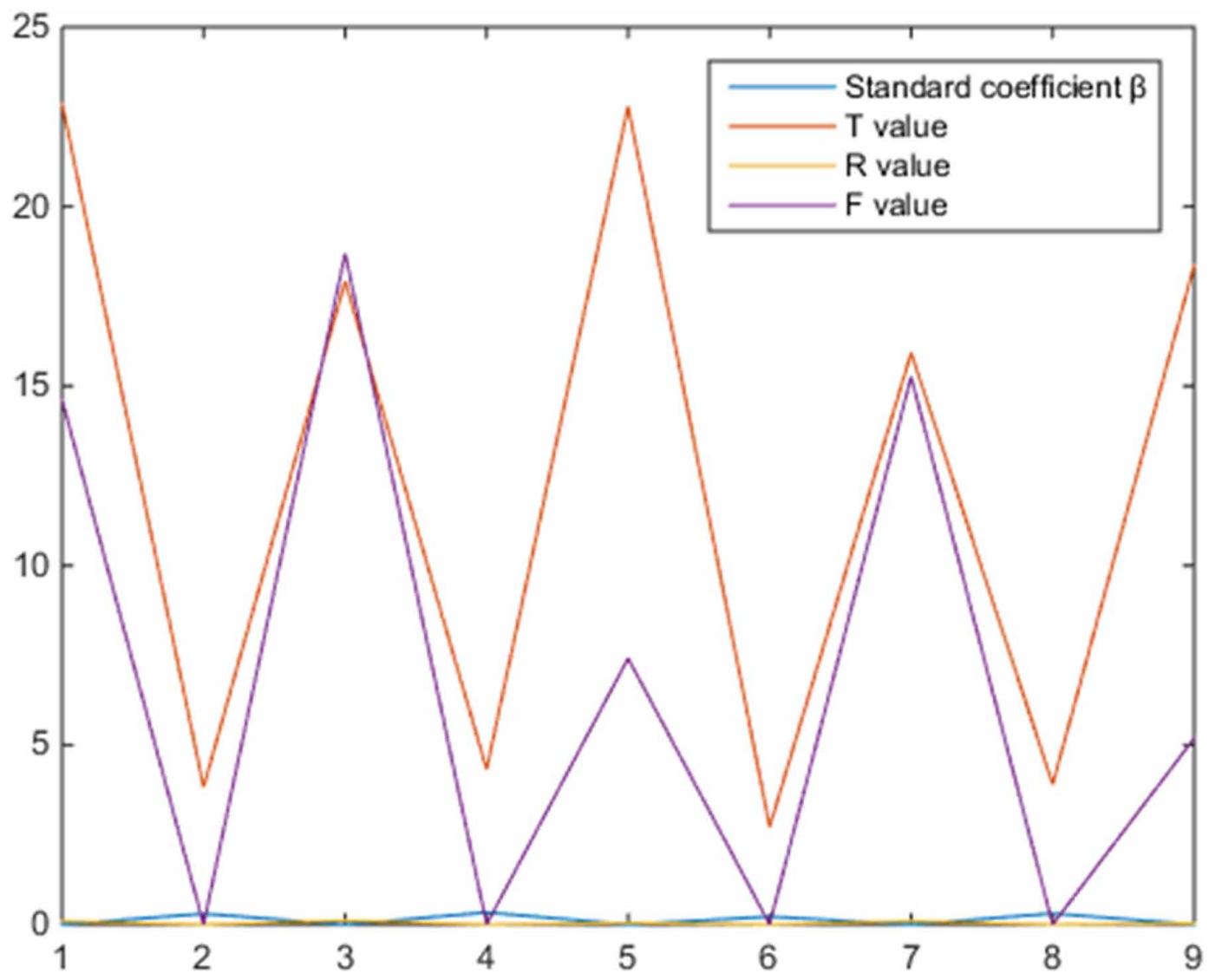

Customer relationship management ability plays an intermediary role in the relationship between e-commerce investment and enterprise performance. The research based on resource-based theory shows that E-B resources / investment itself cannot provide any differentiation advantage different from competitors. Compared with E-B resources / investment itself, the ability to form the best use of e-commerce resources is unique to the enterprise, deeply rooted in the business process that is not easy to transplant. The long-term friendly relationship is ultimately transformed into the ability of 
enterprise performance. Investing in all the foreground and background of applications and processes can help enterprises to provide business transactions, enable enterprises to obtain a large number of E-B technical resources for real-time interaction with customers, online transactions, information sharing with suppliers, timely improve products or services, strengthen two-way communication between enterprises and customers, collect a large number of data resources and analysis, and enable enterprises to develop new products according to existing customer needs or potential needs, maintain long-term good customer relations, and then establish the enterprise value base.

\subsection{Chain Multiple Mediation Analysis}

The direct effect of E-B investment on enterprise performance is not significant as shown in Figure $8(\gamma 4=0.0008, P>0.05,95 \%$ confidence interval is $[-0.0022,0.0037])$, while the indirect effect of E-B investment on CRM capability enterprise performance is significant $(\gamma 1 \gamma 5=0.0016, \mathrm{P}<0.05$, 95\% confidence interval is [0.0006, 0.0031]). The indirect effects of E-B investment, E-B capability, CRM capability and enterprise performance were significant $(\gamma 1 \gamma 2 \gamma 3=0.0023, \mathrm{P}<0.05,95 \%$ confidence interval $[0.0012,0.0038])$.

Figure 8. The chain multiple intermediary function of E-B ability and CRM ability

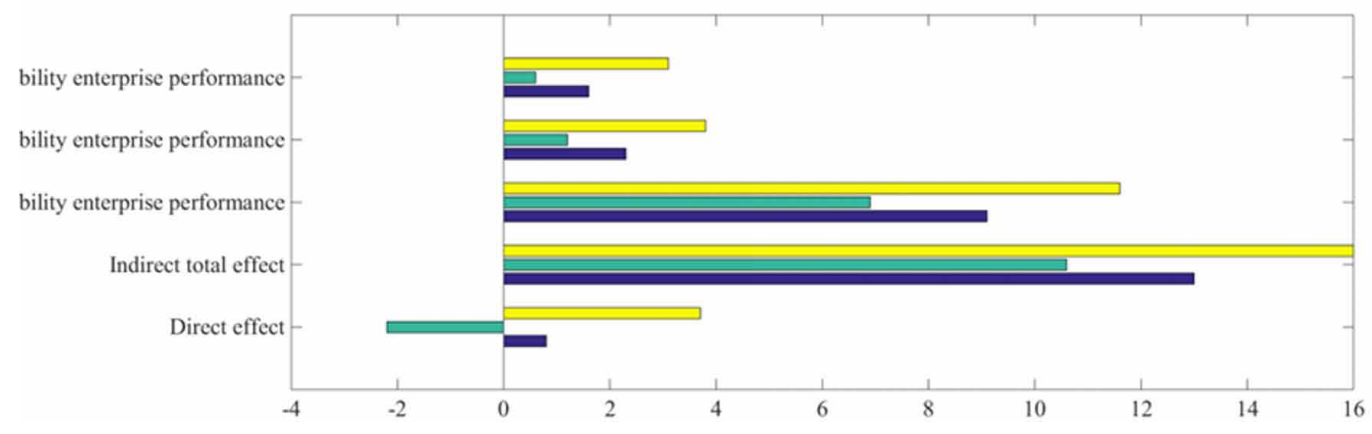

Enterprises can improve E-B ability through E-B technology investment, and then enhance CRM ability to improve enterprise performance. E-commerce resources are the basis for enterprises to obtain differentiated competitive advantages. Integrating these resources and forming their own unique capabilities will bring intangible benefits. E-B technology resources are the main sources of identifying customer needs and obtaining customer consumption behavior information. Making full use of the enterprise ability formed by E-B resources can make the enterprise provide more accurate and timely services for customers, so as to improve the customer relationship management ability. To strengthen the enterprise customer relationship management means to use and analyze customer data, improve customer satisfaction, and ultimately maximize customer benefits. Therefore, through E-B ability to enhance CRM ability, we can realize the impact of E-B investment on enterprise performance.

\section{CONCLUSION}

Aiming at the practical application of e-commerce process, this paper analyzes the relationship among e-commerce capability, e-commerce process performance and enterprise performance. Through a large-scale investigation and interview on the enterprises implementing e-commerce, after processing the recovered data, the empirical research method of structural equation modeling is used to verify the research model, and the nested model test is used to obtain the optimal model experimental results 
show that E-B is positively correlated with $\mathrm{CRM}(\gamma=0.345, \mathrm{t}=4.445, \mathrm{P}<0.05 ; \gamma=0.382, \mathrm{t}=4.997$, $\mathrm{P}<0.05 ; \gamma=0.274, \mathrm{t}=3.449, \mathrm{p}<0.05 ; \gamma=0.341, \mathrm{t}=4.380, \mathrm{p}<0.05 ; \gamma=0.205, \mathrm{t}=2.535, \mathrm{p}<0.05)$. There is no strong positive impact between the use of e-commerce and corporate performance. Although there is a significant impact between e-commerce and corporate performance, it does not have a strong positive impact. In the direct impact model, the direct effect of e-commerce on corporate performance is small, and the value of the path coefficient is 0.30 , indicating that the two There is no very strong positive impact, that is, companies simply using e-commerce cannot effectively improve corporate performance. The initial stage of enterprise investment in e-commerce may not be effective, or even manifested as an increase in cost, but as the enterprise uses e-commerce more and more mature, the tangible and intangible benefits that e-commerce brings to the enterprise will gradually appear, and ultimately manifest as performance Improvement. 


\section{REFERENCES}

Al-Qeed, M. A., Basem, Y., Alsadi, Z., \& Al-Azzam, F. (2017). The Impact of Customer Relationship Management on Achieving Service Quality of Banking Sector of Jordan. Social Science Electronic Publishing, 12(3), 180-190. doi:10.5539/ijbm.v12n3p180

Alamsyah, A., \& Indraswari, A. A. (2017). Social Network and Sentiment Analysis for Social Customer Relationship Management in Indonesia Banking Sector. Advanced Science Letters, 23(4), 3808-3812. doi:10.1166/ as1.2017.9279

Alinejad, G., Emamgholizadeh, S., Zabihi, A., \& Alizadeh, R. (2015). Enterprise Resource Planning System Selection Methodologies in Electronic and Mobile Commerce. Journal of Green Science \& Technology, 2(1), 62-66. doi:10.1166/jgst.2015.1034

Bhat, S. A., \& Darzi, M. A. (2016). Customer Relationship Management: An Approach to Competitive Advantage in The Banking Sector by Exploring The Mediational Role of Loyalty. International Journal of Bank Marketing, 34(3), 388-410. doi:10.1108/IJBM-11-2014-0160

Bogicevic, J., Domanovic, V., \& Krstic, B. (2016). The Role of Financial and Non-Financial Performance Indicators in Enterprise Sustainability Evaluation. Social Science Electronic Publishing, 62(3), 1-13. doi:10.5937/ ekonomika1603001B

Christiam, S. M. A., \& Garcia, C. (2018). Implementation of Kpis for Analyzing Control Loop Performance by Using Pi System of The Osisoft Enterprise. IEEE Latin America Transactions, 16(1), 59-65. doi:10.1109/ TLA.2018.8291455

Cokins, G. (2017). Enterprise Performance Management (Epm) and The Digital Revolution. Performance Improvement, 56(4), 14-19. doi:10.1002/pfi.21698

Edgeman, R. (2015). Strategic Resistance for Sustaining Enterprise Relevance: A Paradigm for Sustainable Enterprise Excellence, Resilience and Robustness. International Journal of Productivity and Performance Management, 64(3), 318-333. doi:10.1108/IJPPM-10-2014-0155

Hsin, H. C., Chen, S. F., Po, W. F., \& Cheng, Y.-C. (2016). The Effects of Relationship Maintenance and Relationship Investment on Self-service Technology Relationship Performance. Information Technology \& People, 29(3), 496-526. doi:10.1108/ITP-08-2014-0171

Hua, N. (2016). E-Commerce Performance in Hospitality and Tourism. International Journal of Contemporary Hospitality Management, 28(9), 2052-2079. doi:10.1108/IJCHM-05-2015-0247

Iqbal, B. A. (2015). E-Commerce in South Asia. Transnational Corporations Review, 4(4), 104-118. doi:10.1 080/19186444.2012.11658349

Jason, S. (2015). Management Innovation for Social Enterprises. Systems Journal IEEE, 9(1), 58-64.

Kizu, T., Wang, Z., \& Manrique, E. E. (2017). Labour Flexibility, Capital Structure and Enterprise Performance. World Employment \& Social Outlook, 2017(3), 41-72. doi:10.1002/wow3.116

Kyung, L. H., Duk, Y. H., Jeoung, K. S., \& Kyo, S. Y. (2016). Factors Affecting University-Industry Cooperation Performance: Study of The Mediating Effects of Government and Enterprise Support. Journal of Science \& Technology Policy Management, 7(2), 233-254. doi:10.1108/JSTPM-08-2015-0029

Li, X., Ren, X., \& Xu, Z. (2016). Management of Competition among Sellers and Its Performance Implications for Business-To-Business Electronic Platforms. Nankai Business Review International, 6(2), 199-222. doi:10.1108/ NBRI-02-2015-0006

Lin, C. (2017). The Evolution of E-Commerce Payment. Technology and Investment, 08(1), 56-66. doi:10.4236/ ti.2017.81005

Mamun, A. A., \& Nasir, W. M. N. B. W. M. (2017). Effect of Market and Interaction Orientations on Innovation Orientation and Enterprise Performance. Advanced Science Letters, 23(4), 2925-2928. doi:10.1166/asl.2017.7608 
Navimipour, N. J., \& Soltani, Z. (2016). The Impact of Cost, Technology Acceptance and Employees' Satisfaction on The Effectiveness of The Electronic Customer Relationship Management Systems. Computers in Human Behavior, 55(C), 1052-1066. doi:10.1016/j.chb.2015.10.036

Octavia, A., Zulfanetti, , \& Erida, . (2017). Influence Models of Entrepreneurial Orientation, Entrepreneurship Training, and Business Performance of Small Medium Enterprises. Advanced Science Letters, 23(8), 7232-7234. doi:10.1166/asl.2017.9338

Orenga-Roglá, S., \& Chalmeta, R. (2016). Social Customer Relationship Management: Taking Advantage of Web 2.0 and Big Data Technologies. SpringerPlus, 5(1), 1462. doi:10.1186/s40064-016-3128-y PMID:27652037

Prisha, P., Neo, H.-F., Ong, T.-S., \& Teo, C.-C. (2017). E-Commerce Security and Identity Integrity: The Future of Virtual Shopping. Journal of Computational and Theoretical Nanoscience, 23(8), 7849-7852.

Rahim, R. A., Nik, H. N. M., \& Masrom, M. (2017). Innovation and Knowledge Management as The Catalyst of Small Medium Enterprise's Performance: A Conceptual Paper. Advanced Science Letters, 23(4), 2727-2730. doi:10.1166/asl.2017.7581

Shami, M., Sakhaee, N., \& Shahbaznezhad, H. (2015). Mechanisms of Customer Knowledge Management in E-Commerce Websites. Research Journal of Information Technology, 1(2), 86-93.

Shan, W., Cavusoglu, H., \& Deng, Z. (2016). Early Mover Advantage in E-Commerce Platforms with Low Entry Barriers: The Role of Customer Relationship Management Capabilities. Information \& Management, 53(2), 197-206. doi:10.1016/j.im.2015.09.011

Soltanizadeh, S., Siti, Z. A. R., Golshan, N. M., \& Wan, K. W. I. (2016). Business Strategy, Enterprise Risk Management and Organizational Performance. Management Research Review, 39(9), 1016-1033. doi:10.1108/ MRR-05-2015-0107

Sun, J., \& Yano, G. (2015). Finance and Enterprise Performance: Does Ethnicity Make a Difference? Hitotsubashi Journal of Economics, 56(2), 197-212.

Wang, Y. Y., Luse, A., Townsend, A. M., \& Mennecke, B. E. (2015). Understanding the Moderating Roles of Types of Recommender Systems and Products on Customer Behavioral Intention to Use Recommender Systems. Information Systems and e-Business Management, 13(4), 769-799. doi:10.1007/s10257-014-0269-9

Wu, S. I. (2016). The Impact of Customer Relationship Management and Internal Marketing on Business Performance: A Comparison of Lodging Industries. Total Quality Management \& Business Excellence, 27(1-2), 17-33. doi:10.1080/14783363.2014.935567

Xun, J. (2015). British Smes' E-Commerce Technological Investments and Firm Performance: An Rbv Perspective. Technology Analysis and Strategic Management, 27(5), 586-603. doi:10.1080/09537325.2015.1 019453

Yili Sun was born in Shouguang, Shandong, P.R. China, in 1988. She received her doctorate degree from Suwon University, South Korea. Now, she works in College of Economics and Management, Weifang University of Science and Technology. Her research interests include financial management, E-commerce, and regional economy.

Ping Wang received a PhD degree in Industrial Information System from Seoul National University of Science and Technology in August 2015. Dr. Ping Wang is currently Assistance Professor in School of Economics and Management, Weifang University of Science and Technology, China. His research interests include internet finance, technology financial innovation, pension financial innovation and industrial information system. He has published more than 10 papers at different journals. He is now presiding a project of the National Key R\&D Program of China: Special Project for Intergovernmental International Scientific and Technological Innovation Cooperation, and also presided a project of the Humanities and Social Science foundation of Ministry of Education of China, and many other provincial-level projects in China. 